\title{
Pathophysiological aspects and management workflow of coronary microvascular obstruction in ST-segment elevation myocardial infarction
}

\author{
Giancarla Scalone, Giampaolo Niccoli, Filippo Crea \\ Institute of Cardiology, Catholic University of the Sacred Heart, Rome, Italy
}

\begin{abstract}
Restoring blood flow to ischemic but viable myocardium and reducing infarct size constitute the goals of reperfusion therapy with fibrinolytic drugs or primary percutaneous intervention in patients with ST-segment elevation myocardial infarction (STEMI). However, in a sizable proportion of patients, this intervention gains to reopen the obstructed epicardial coronary artery but does not achieve myocardial reperfusion because of coronary microvascular obstruction phenomenon (CMVO). In the last years, consistent evidence has pointed out how CMVO has a negative impact on outcome in patients with acute STEMI. Of note, most of the trials in this setting, mainly targeting reperfusion damage, have failed to show beneficial effects. In this article we provide a revision of mechanisms, diagnosis and prognosis of CMVO in acute STEMI, also pointing out the need of an integrated approach in order to prevent and treat CMVO in the different time windows of the acute event.
\end{abstract}

\section{Introduction}

ST-segment elevation myocardial infarction (STEMI), usually resulted from acute thrombotic occlusion of a coronary artery, still represents one of the main causes of death. ${ }^{1}$ In this context, restoring blood flow to ischemic but viable myocardium, as well as reducing infarct size (IS), constitute the goals of reper-

Correspondence: Giancarla Scalone and Filippo Crea, Institute of Cardiology, Catholic University of the Sacred Heart, Largo F. Vito 1, 00168 Rome, Italy.

Tel.: +39.06.30154187 - Fax: +39.06.3055535.

E-mail: gcarlascl@gmail.com; fcrea@rm.unicatt.it

Key words: Microvascular dysfunction; acute myocardial infarction; ischemic-reperfusion related injury; distal embolization.

Contributions: GS drafted the manuscript; GN critically revised the manuscript; FC critically revised the manuscript and approved it.

Conflict of interest: the authors declare no potential conflict of interest.

Received for publication: 8 July 2015.

Accepted for publication: 24 September 2015.

This work is licensed under a Creative Commons Attribution NonCommercial 4.0 License (CC BY-NC 4.0).

C Copyright G. Scalone et al., 2016

Licensee PAGEPress, Italy

Italian Journal of Medicine 2016; 10:10-22

doi:10.4081/itjm.2016.622 fusion therapy with fibrinolytic drugs or primary percutaneous intervention (PCI). ${ }^{2}$ However, despite several efforts provided to reduce time to treatment and maximize myocardial salvage, in-hospital mortality has remained unchanged in this setting of patients. ${ }^{3}$ In this context, it has to be taken into account that, in a sizable proportion of patients ranging from $10 \%$ to $60 \%$, the reopening of the obstructed epicardial coronary artery is not associated with myocardial reperfusion because of coronary microvascular obstruction (CMVO). ${ }^{4}$ Moreover, consistent evidence showed as CMVO has a negative impact on outcome, being associated with adverse left ventricular remodelling, late repeat hospital stays for heart failure, and death. In this article we point out mechanisms, diagnosis and prognosis of CMVO in acute STEMI, also emphasizing the need of an integrated approach for prevention and treatment of CMVO in different time windows.

\section{Mechanisms of coronary microvascular obstruction}

In the past years, four interacting mechanisms have emerged as principal causes of CMVO in humans: ischemia-related injury, reperfusion-related injury, distal embolization and individual susceptibility of the microcirculation to injury (Figure 1). Recently, a pre-existing impairment of the myocardial microcirculation, principally due to cardiovascular risk factors, has been shown to yield greater vulnerability to PCIrelated myocardial injury as well as a poor long-term outcome. ${ }^{5,6}$ In particular, a pre-existing transient or permanent microcirculatory dysfunction may con- 
tribute to the development and prognosis of acute coronary syndrome (ACS) via reduction of coronary blood flow, leading to an alteration of shear stress and thereby worsening of endothelial function at epicardial level as well as aggravation of thrombus formation. ${ }^{7}$

Ischemic and reperfusion related injuries have been translated to humans from the animal models with a first description by Kloner et al. ${ }^{8}$ In particular, electron microscopic analysis after 90-min coronary occlusion followed by reperfusion, revealed severe capillary damage, endothelial protrusions and blebs blocking the capillary lumen, and endothelial gaps with extra vascular erythrocytes. ${ }^{8}$ The most important clinical predictors of ischemia-related injury are ischemia duration and extent. ${ }^{9}$

When ischemia lasts more than $3 \mathrm{~h}$, ischemia-associated injury is potentiated by reperfusion injury. ${ }^{10}$ In particular, lethal reperfusion injury (myocardial necrosis due to reperfusion) and CMVO play a major role. Neutrophil-platelet aggregates, which represent a major source of oxidants, proteolytic enzymes and pro-inflammatory mediators, can cause CMVO by further obliteration of vessel lumen. ${ }^{11}$ On the other hand, reperfusion also stimulates the production of radical oxygen species by mitochondria of cardiomyocytes that lead to the opening of mitochondrial membrane permeability transition pores, calcium overload, mitochondrial swelling and cell disruption. ${ }^{11}$ Moreover, endothelial cells can regulate leucocyte function by the expression of adhesion molecules, e.g., intercellular adhesion molecule-1 or P-selectin, and by the release of soluble factors like nitric oxide, prostacyclin, endothelin. ${ }^{12}$

Again, ischemia followed by reperfusion can disrupt the endothelial barrier and damage the microvasculature, facilitating extravasation of blood cells upon reperfusion and eventually causing intra-myocardial hemorrhage (IMH) ${ }^{13}$ Of note, patients with this more severe form of CMVO seem to have a worse outcome than patients with CMVO but without IMH. ${ }^{14}$

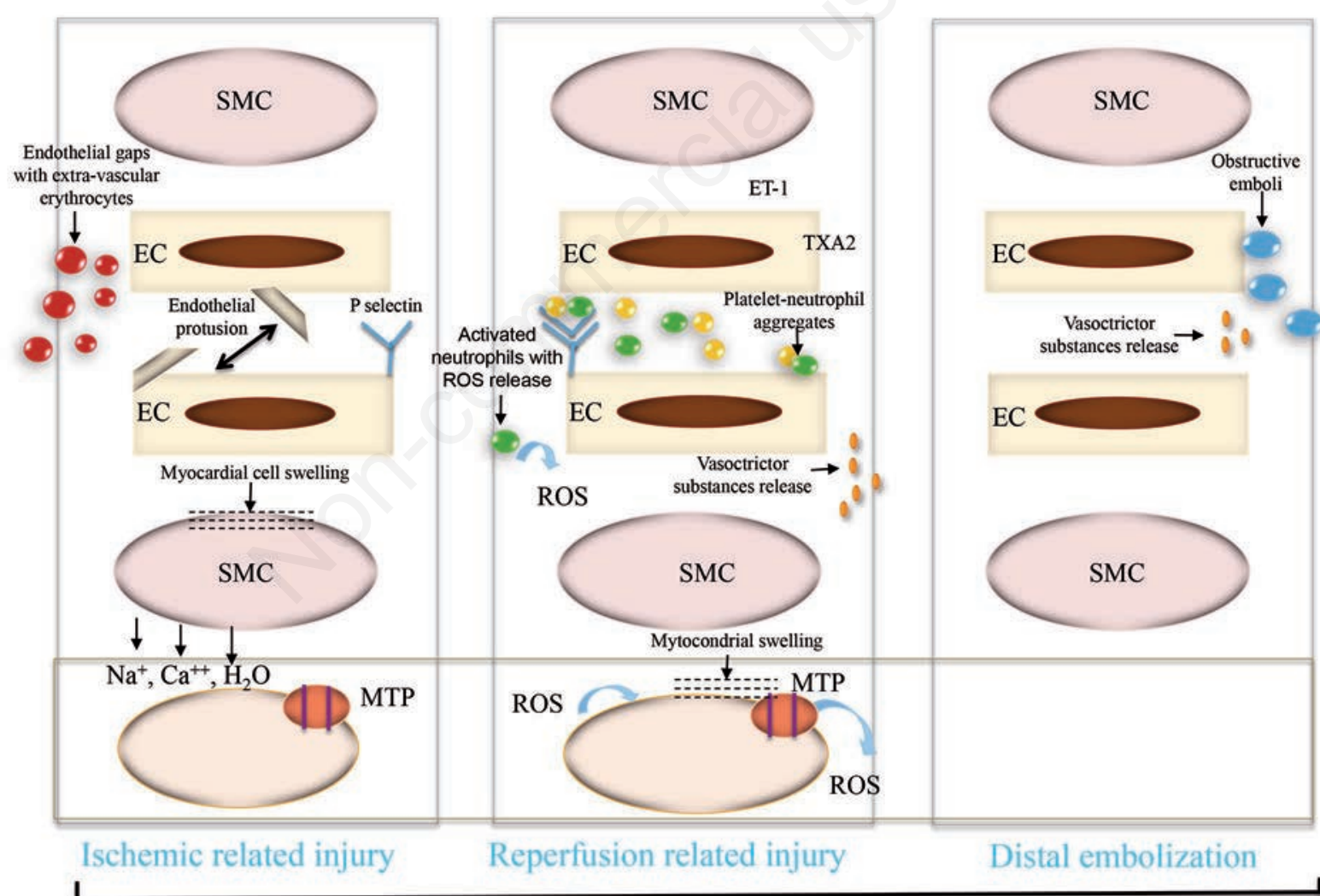

Individual susceptibility

Figure 1. The 4 interacting mechanisms involved in the pathogenesis of coronary microvascular obstruction in humans: Ischemic related injury: it is characterized by severe capillary damage, endothelial protrusions, endothelial gaps with extra vascular erythrocytes (in red) and expression of P-selectin. Reperfusion related injury: the principal determinants are represented by neutrophils (in green), endothelin-1 (ET-1), thomboxane-A2 (TXA2), platelets (in yellow) and inflammatory mediators (in brown). Distal embolization: distal embolization (in blue) of plaque and thrombus material may obstruct mechanically the microcirculation, but it is also a source of vasoconstrictors and pro-coagulant substances. SMC, smooth muscle cell; EC, endothelial cell; ROS, radical oxygen species; MTP, membrane permeability transition. 
A third important mechanism of CMVO is represented by distal physical and chemical substances embolization. Emboli of different sizes can originate from epicardial coronary thrombus and from fissured atherosclerotic plaques during primary PCI. However, spontaneous embolization can be suspected also before vessel manipulation. Of note, the effect of angiographically visible distal embolization on IS seems to be time-dependent. ${ }^{15}$

Both plaque and thrombus features are associated with risk of distal embolization. In particular, a high thrombus burden, as well as the presence of a lipid rich plaque and plaque erosion are associated with the occurrence of distal embolization. ${ }^{16}$

Finally, another component of CMVO is represented by the individual susceptibility to microvascular dysfunction, maybe related to the function, as well as to the structure and the density of the microcirculation. ${ }^{17}$ Genetic factors, like 1976T.C polymorphism of the adenosine $2 \mathrm{~A}$ receptors gene, may modulate adenosine-induced vasodilation. ${ }^{18}$ Another element acting on the individual susceptibility to CMVO is the presence of ischemic preconditioning (IPC), which seems to protect both the myocardium and the coronary microcirculation. ${ }^{17}$ Accordingly, pre-infarction angina might help preventing CMVO by inducing IPC. Interestingly, beneficial effect of pre-infarction angina may be blunted in humans due to risk factors or drugs therapy affecting unfavorably IPC, ${ }^{19}$ while chronic nitrate therapy seems to stimulate IPC. ${ }^{20}$

\section{Diagnosis of coronary microvascular obstruction}

Based on a combination of angiographic and electrocardiographic indexes, a reasonable estimate of patients who get optimal myocardial reperfusion is approximately $35 \% .{ }^{17}$ Of note, due to its dynamic nature, in $50 \%$ of cases CMVO is irreversible, while in the remaining $50 \%$ it is reversible. ${ }^{21}$ The diagnostic indexes may be classified as invasive or no-invasive tools (Figure 2).

\section{Invasive indexes of coronary microvascular obstruction}

The gold standard method for assessing microvascular function is the direct measurement of coronary flow reserve (CFR) using intra-coronary (IC) Doppler wire in response to a vasodilator such as adenosine. In particular, the typical CMVO pattern is characterized by: systolic retrograde flow, diminished systolic anterograde flow and rapid deceleration of diastolic flow. The attenuated CFR response post PCI seems to be associated with future cardiovascular events. ${ }^{22}$

Recently, several studies have tested other invasive indexes in comparison with CFR, e.g., index of microvascular resistance and hyperemic microvascular resistance index, pointing out promising data about reproducibility and prognostic value. ${ }^{23,24}$ All together, these insights from clinical pathophysiology could support therapeutic approaches beyond the primary PCI procedure itself.

Thrombolysis in myocardial infarction (TIMI) score grading system describes the rate of blood flow in the epicardial vessels, ranging between no flow at all (grade 0) to a normal flow rate (grade III). TIMI flow $<3$ is a marker of both CMVO and of larger IS and has been shown to affect prognosis both at short and long term follow up. ${ }^{25}$ TIMI frame count index, defined as the number of frames required for contrast medium to reach a standardized distal landmarks, is able to stratify the prognosis of patients exhibiting TIMI flow 3 and correlate with invasive assessment of CFR. ${ }^{26}$

In the next years, angiographic methods based on the kinetics of dye penetration within the myocardium (myocardial blush), the myocardial blush grade (MBG) and TIMI myocardial perfusion grade (TMPG), shifted the attention from the epicardial flow to the microcirculatory flow by angiography. ${ }^{27,28}$

MBG is a densitometric method scored on a scale of 0 to 3, with higher scores indicating better perfusion. The TMPG assesses microvascular clearance of contrast medium and is scored again on a scale of 0 to 3. Both MBG and TMPG are useful to risk stratify patients having final TIMI flow 3 . Thus, it is becoming common practice to define angiographic CMVO, as follows: TIMI flow grade $<3$ or 3 with an MBG or TMPG 0 to $1 .^{29}$

\section{No-invasive indexes of coronary microvascular obstruction}

After primary PCI, incomplete ST resolution (STR) has been related to CMVO and worse clinical outcome. ${ }^{30}$ However, a consensus is still lacking about which leads to analyse, the optimal timing of electrocardiogram (ECG) analysis, and whether standard ECG or continuous ECG monitoring is preferable. Assessment of single lead STR showing maximum ST elevation at baseline seems to be as accurate as the sum STR measurements, ${ }^{31}$ whereas a recent study showed how residual ST-segment elevation can be considered as an independent marker of CMVO ${ }^{32} \mathrm{Of}$ note, angiography and ECG are obtained at two different times after primary PCI and they may reflect different aspects of myocardial reperfusion, with angiography looking more at the coronary microcirculation and ECG more at myocardial cells. ${ }^{17}$

Myocardial contrast echography (MCE) is a method that utilizes ultrasound to visualize contrast microbubbles with a rheology similar to that of red 
blood cells that freely flow within patent microcirculation. In particular, lack of intra-myocardial contrast opacification, due to CMVO, is able to predict functional recovery after STEMI. ${ }^{33}$

Cardiac magnetic resonance (CMR) allows an accurate quantification and localization of CMVO and IS relative to the entire left ventricle. ${ }^{34}$ In particular, CMVO can be typified as: i) lack of gadolinium enhancement during first pass $(<2 \mathrm{~min})$; and ii) lack of gadolinium enhancement within a necrotic region, identified by late gadolinium hyper-enhancement (after 10-15 min). First pass (early) CMVO is more sensitive that late $\mathrm{CMVO}$, as the latter underestimates the extent of CMVO. Of note, CMR may give additional hints to the presence of IMH. ${ }^{13,14}$

Other imaging techniques under investigation for CMVO detection include myocardial scintigraphy or hybrid positron emission tomography-computed tomography. ${ }^{35}$

\section{Prognosis of coronary microvascular obstruction}

Indexes of CMVO are able to predict adverse left ventricular remodelling and mortality after primary PCI (Table 1) ${ }^{21,36-43}$ In particular, TIMI flow $\leq 2$ is associated with an increased risk of adverse remodelling at 6 months $^{36}$ and of 5-year mortality. ${ }^{37}$ MBG 0-1 raised the risk of adverse remodelling at 6 months $^{38}$ and of total mortality after 16 months of follow-up. ${ }^{39}$ MCE detected CMVO was associated with an enhancement of the risk of adverse remodelling at 6 months ${ }^{33}$ and of cardiac death after 46 months. ${ }^{40} \mathrm{CMR}$ detected CMVO increased the risk of adverse remodelling at 6 months ${ }^{41}$ and of death. ${ }^{42}$ The lack of STR

\section{Invasive indexes}

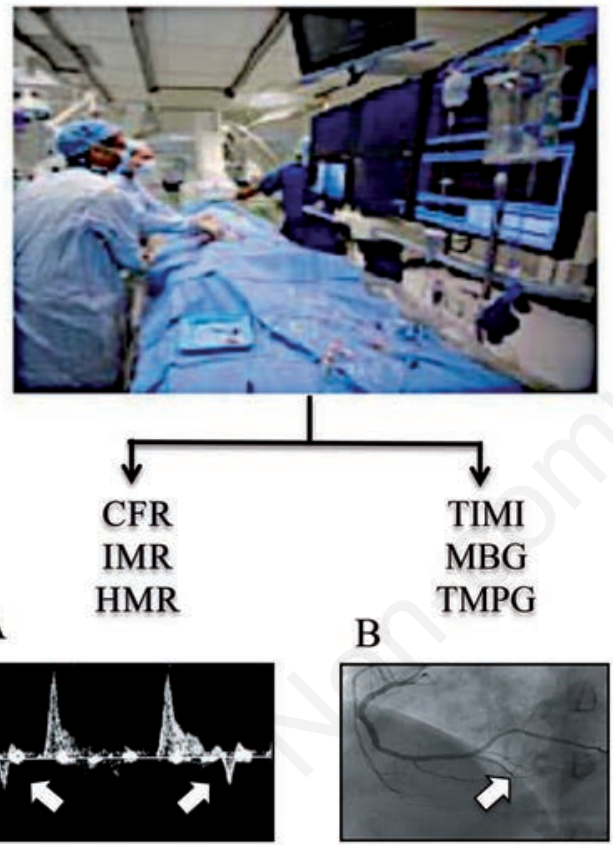

\section{No invasive indexes}

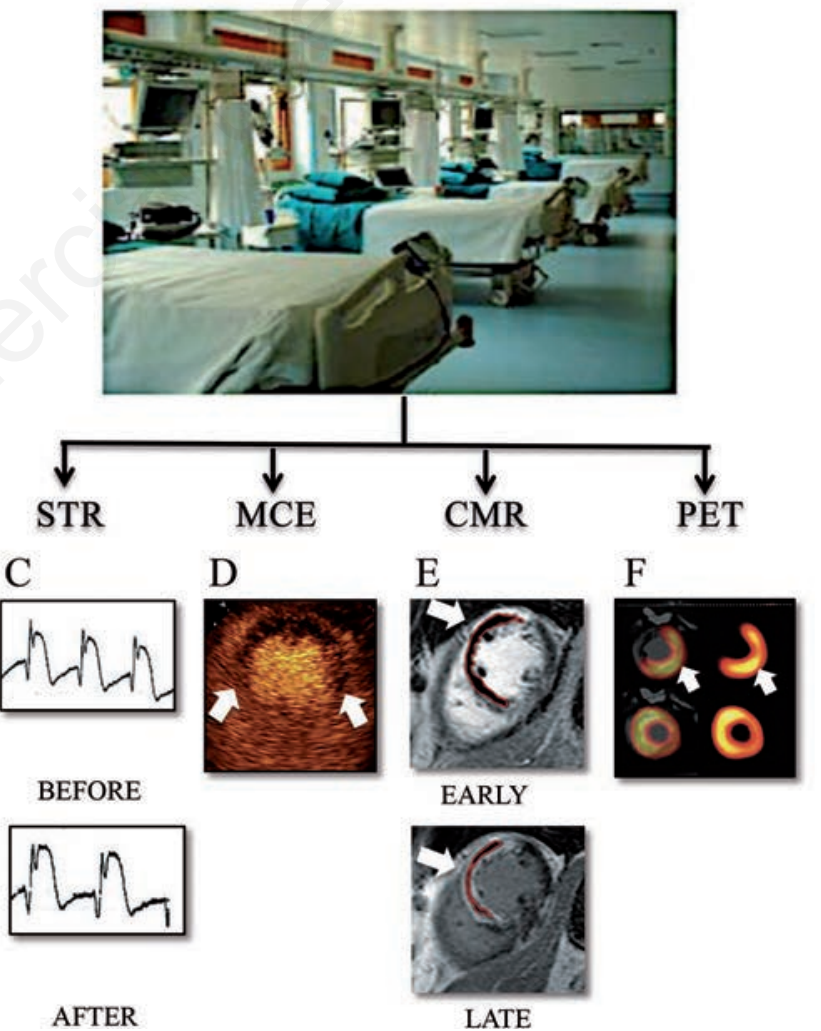

Figure 2. Invasive indexes of coronary microvascular obstruction (CMVO): coronary flow reserve (CFR) (systolic retrograde flow, panel $A$, indicated by white arrows); microvascular resistance (IMR) and hyperemic microvascular resistance (HMR). Thrombolysis in myocardial infarction (TIMI) flow score, myocardial blush grade (MBG) and TIMI myocardial perfusion grade (TMPG) (angiographic CMVO, panel B, indicated by white arrow in the posterior descending artery of the right coronary artery). No-invasive indexes of CMVO: ST-segment resolution (STR) (panel C, at the top, for the ST before opening infarct related artery and at the bottom for the ST after opening infarct related artery during CMVO); myocardial contrast echocardiography (MCE) (lack of intra-myocardial contrast opacification, panel $D$, indicated by white arrows). Cardiac magnetic resonance (CMR) (lack of gadolinium enhancement during first pass, image $\mathrm{E}$, at the top, indicated by white arrow and lack of gadolinium enhancement within a necrotic region, panel $\mathrm{E}$, at the bottom, indicated by white arrow). The hybrid positron emission tomography/cardiac computed tomography (PET) (panel $\mathrm{F}$, indicated by white arrows). 
raised the risk of total mortality after 30 days but failed to predict adverse left ventricular remodelling. ${ }^{36}$ The combination of poor MBG (0-1) and lack of STR exhibited an additive effect on the risk of total mortality after 1 year, thus suggesting that angiographic and ECG indexes of CMVO may emblematize different pathogenetic mechanisms. ${ }^{43}$

\section{Treatment strategies in different time windows}

During the years, many efforts have been provided in order to detect an effective strategy to prevent and approach CMVO. Of note, currently, no treatment strategy has really proved in a randomized multicenter trial to be beneficial for the prevention or treatment of CMVO.

Hence, we will expose all therapies with an evidence and/or general agreement of possible utility in treating CMVO that need to be tested in large trials and all those that still need confirmation due to limited or conflicting evidence and/or divergence of opinion about their utility. Furthermore, we will propose a classification following the same time windows of treatment commonly utilized for STEMI patients (Table 2 and Figure 3). ${ }^{4-80}$

Three phases may thus be identified: the first time window extends until hospital admission for STEMI, the second time window takes place in catheterization laboratory, and the third time window unfolds in the Coronary Care Units (CCU), after catheterization laboratory.

\section{Before catheterization laboratory}

Ongoing statin therapy at the time of STEMI was associated with a lower rate of CMVO, and better functional recovery of myocardial function after 6 months of follow-up as compared to patients not on statin. ${ }^{44}$ Moreover, the administration of high doses of statins prior to primary $\mathrm{PCI}$ seems to improve CMVO as compared to that of low doses. ${ }^{45}$

Regarding $\beta$-blockers, intravenous (IV) metoprolol administered in ambulance in patients with anterior STEMI on Killip class II or less, has shown to reduce IS, increase left ventricular ejection fraction (LVEF) and reduce the need for cardioverter-defibrillator implantation, with fewer admissions due to heart failure after 2 years. ${ }^{46}$

Among antiplatelet drugs commonly used in STEMI patients, pre-hospital abciximab administration seems to be useful. ${ }^{47}$ Of note, the upstream administration of abciximab with half-dose reteplase significantly reduces IS but does not have any overall clinical benefits in primary study end point at 90 days as well as in mortality at 1 year. ${ }^{48}$ On the other hand, a routine prehospital initiation of high-bolus dose tirofiban might improve STR and clinical outcome after PCI. ${ }^{49}$

Regarding remote ischemic conditioning (RIPC), Botker et al. showed that, applying three 5-min cycles of brief ischemia and reperfusion of the upper arm by using blood pressure cuff, myocardial salvage was increased in STEMI patients undergoing primary PCI, especially in those with a large area at risk..$^{50}$ Of note, morphine added to RIPC protocol was able to further improve STR. ${ }^{51}$

Results of studies with the glucose-insulin-potassium (GIK) in the setting of STEMI have been controversial. ${ }^{52,53}$ Indeed, if CREATE ECLA provided neutral results with no difference in 30 days mortality with GIK as compared to placebo, ${ }^{52}$ the recent IMME-

Table 1. Main study showing the prognostic role of coronary microvascular obstruction after primary percutaneous coronary intervention.

\begin{tabular}{|c|c|c|c|c|}
\hline CMVO diagnostic index & Year of publication & Author & Patients (n) & Risk measure \\
\hline \multicolumn{5}{|l|}{ Risk of adverse remodeling } \\
\hline TIMI flow & 2004 & Bax et al. ${ }^{36}$ & 73 & OR $5.6,95 \%$ CI $1.40-22$ \\
\hline MBG & 2006 & Araszkiewicz et al..$^{38}$ & 145 & OR $3.15,95 \%$ CI $1.35-7.31$ \\
\hline MCE & 2008 & Galiuto et al..$^{21}$ & 110 & OR $12.7,95 \%$ CI $2.65-61.2$ \\
\hline CMR & 2012 & Lombardo et al..$^{41}$ & 41 & OR $3.1,95 \%$ CI $1.45-6.64$ \\
\hline \multicolumn{5}{|l|}{ Risk of death } \\
\hline TIMI flow & 2010 & Ndrepepa et al. ${ }^{37}$ & 1406 & OR $1.66,95 \%$ CI $1.17-2.36$ \\
\hline MBG & 2003 & Henriques et al..$^{39}$ & 294 & OR $4.2,95 \%$ CI $2.1-8.5$ \\
\hline $\mathrm{MCE}$ & 2004 & Bolognese et al..$^{40}$ & 124 & OR $10.7,95 \%$ CI $2.4-47$ \\
\hline CMR & 2010 & De Waha et al. ${ }^{42}$ & 438 & HR $5.12,95 \%$ CI $1.09-24.06$ \\
\hline ECG & 2005 & Sorajja et al. ${ }^{43}$ & 456 & OR $2.5,95 \%$ CI $1.02-6.3$ \\
\hline
\end{tabular}


DIATE trial showed reduction in IS and lower rate of in-hospital mortality and cardiac arrest in patients randomized GIK than in controls. ${ }^{53}$ Similarly, the role of chronic treatment and early re-administration of ACE inhibitors or nitrates, both associated with better reperfusion in small retrospective studies, should be tested on a large scale. ${ }^{54,81}$

\section{In the catheterization laboratory}

Adenosine can prevent CMVO through several mechanisms. Differences in way of administration, timing and dosages may explain the discrepancies observed in the studies. Indeed, if IV adenosine started before reperfusion might improve the outcome when given early ( $<3.2 \mathrm{~h}$ from chest pain onset) as compared to placebo, ${ }^{55}$ other reports have provided mixed results regarding the role of IC adenosine. ${ }^{56,57}$ In the REOPEN-AMI trial, we found high dosages of IC adenosine, given after thrombus aspiration through the aspiration catheter, improved STR and enzymatic IS as compared to placebo or sodium nitroprusside, which translated in a reduction of major adverse cardiac events (MACEs) and a better left ventricular remodelling at 1 -year follow-up. ${ }^{58,59}$

Moreover, atrial natriuretic peptide (ANP), cyclosporine and exenatide, known to have cardioprotective effects, have shown beneficial effects on IS while the effect on indexes of CMVO is neutral or not reported. ${ }^{60-62}$

In particular, ANP, which activates the RISK cardioprotective pathways, limited enzymatic IS and improved LVEF. $^{60}$

Again, exenatide, a glucagon-like peptide-1 agonist started 15 min before primary PCI and given intravenously for $6 \mathrm{~h}$ post procedure, increased salvage index but 30-day clinical events were similar as compared to placebo. ${ }^{62}$

Cardioprotection by mechanical remote conditioning (3 cycles of ischemia/reperfusion of the lower limb) at the time of primary PCI reduced enzymatic IS, and was associated with an improvement of T2weighted edema volume assessed by CMR and STR as compared to conventional primary PCI. ${ }^{63}$
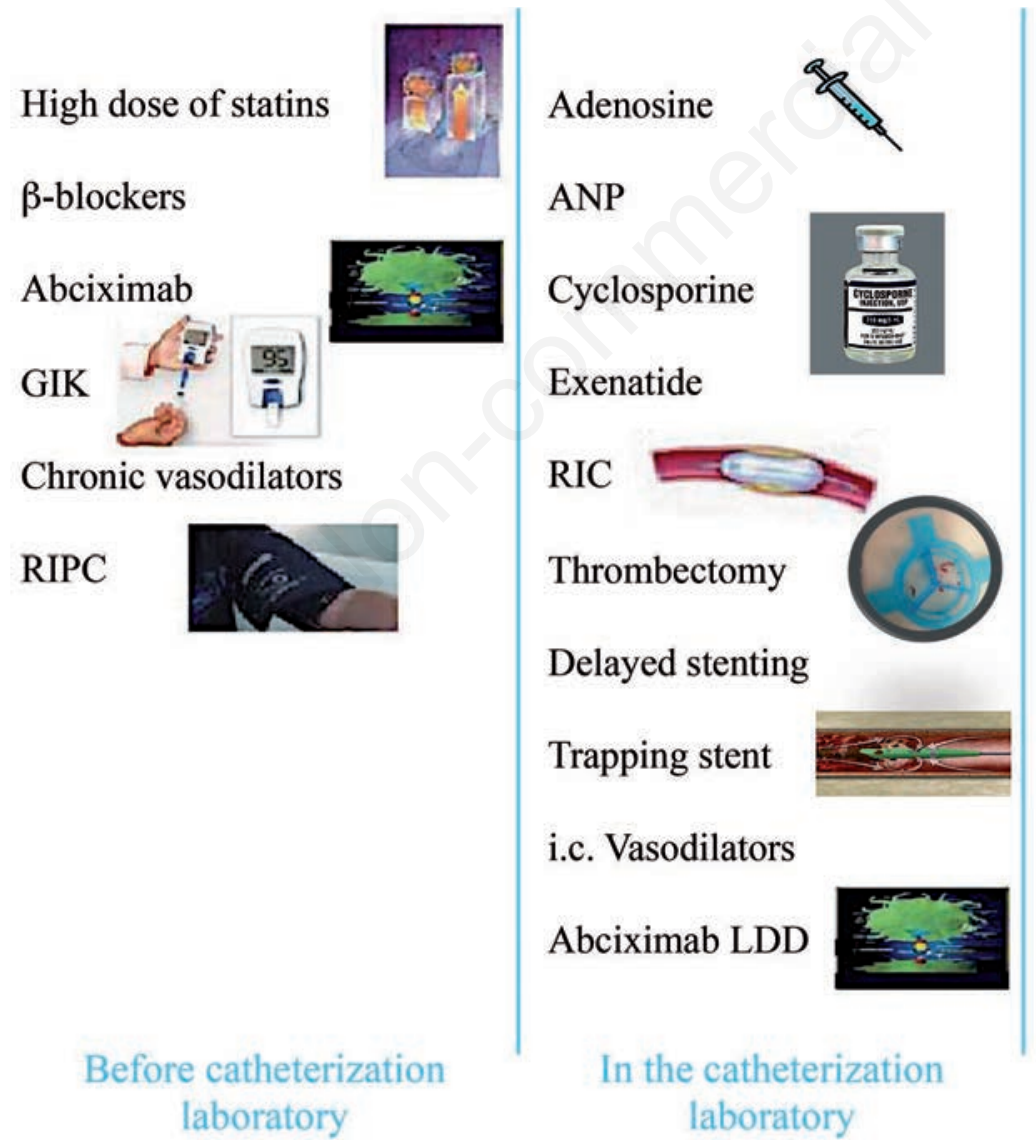

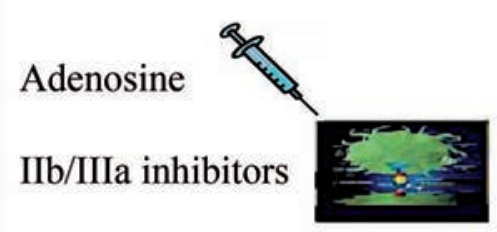

ANP

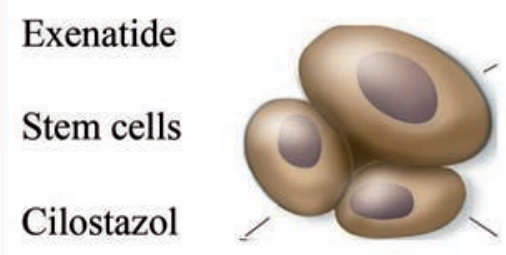

Vasodilators

Metabolic drugs

\section{After catheterization laboratory}

Figure 3. Current treatments of coronary microvascular obstruction in different time windows: before catheterization laboratory, in the catheterization laboratory and after catheterization laboratory. ANP, atrial natriuretic peptide; GIK, glucose insulin potassium; RIC, remote ischemic conditioning; RIPC, remote ischemic pre-conditioning; i.c., intra-coronary; LDD, local drug delivery. 


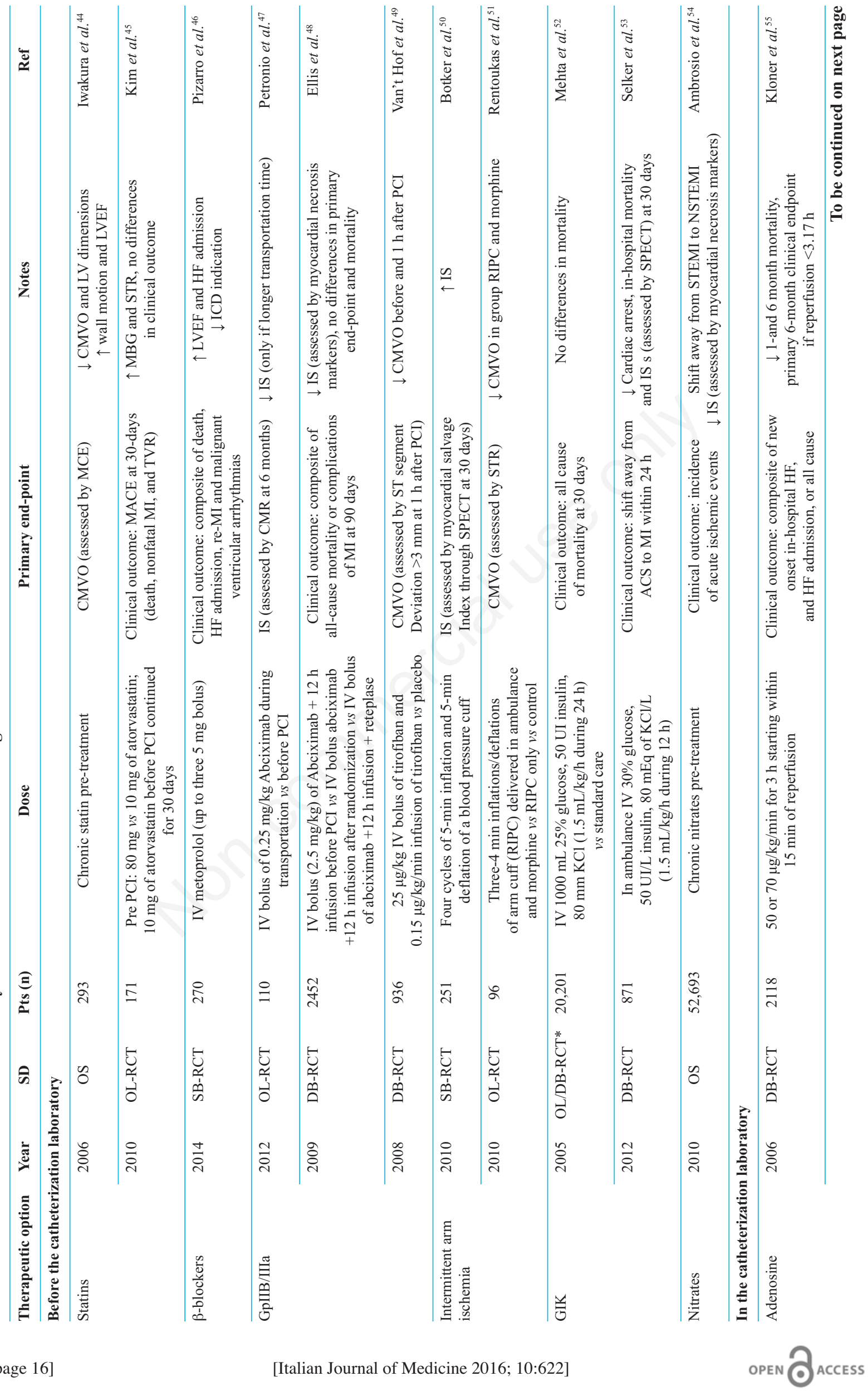




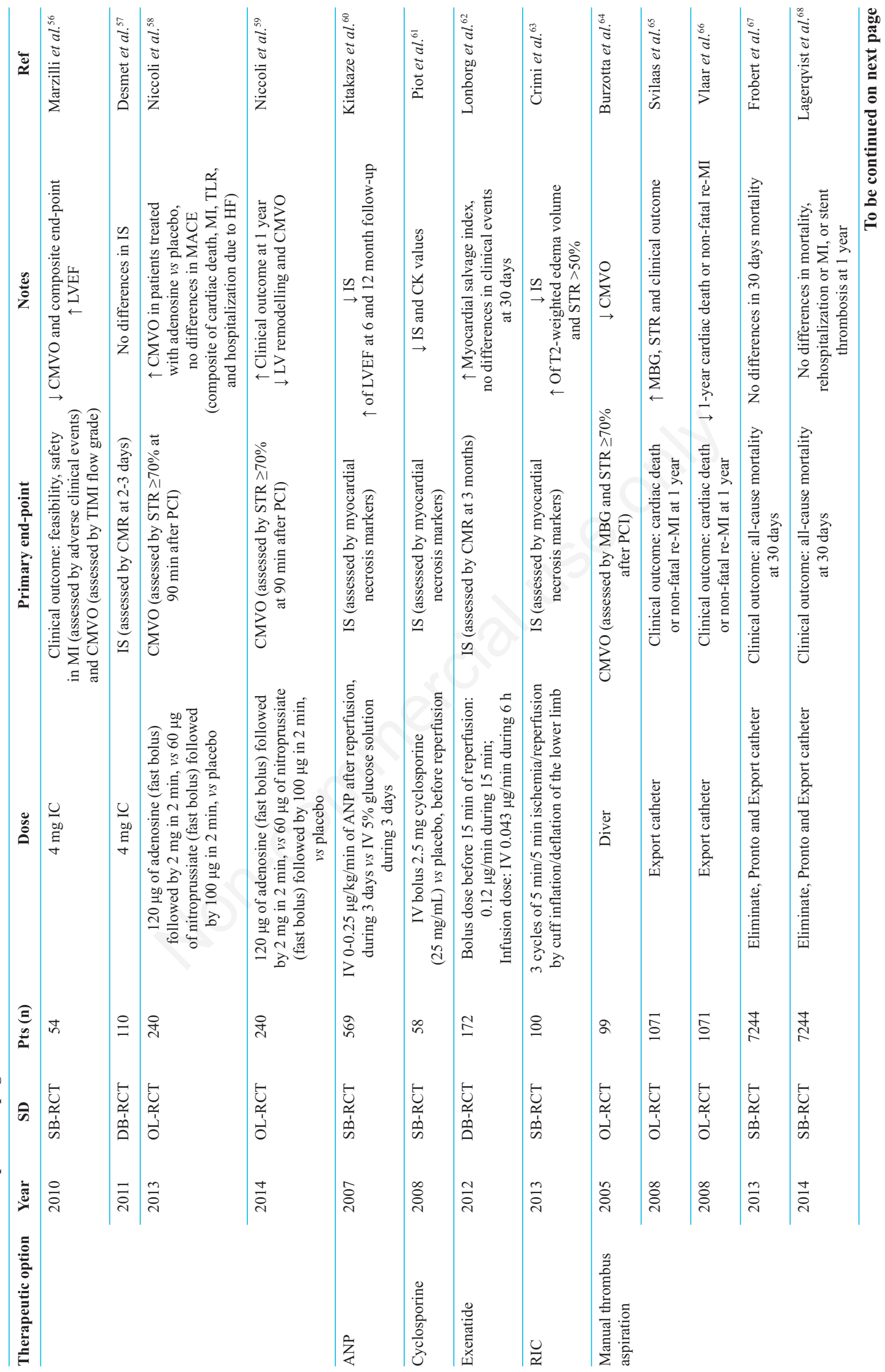




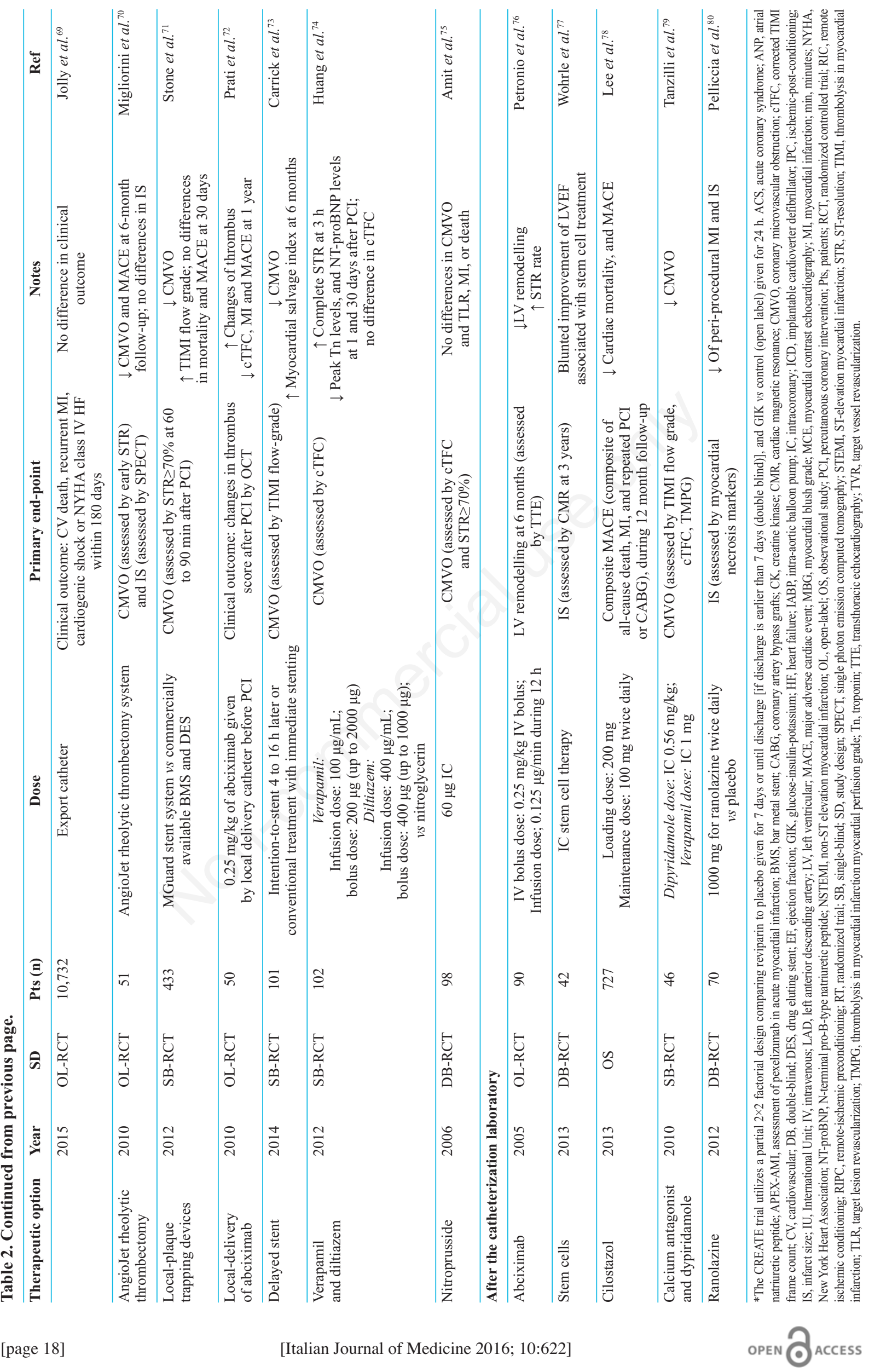


If the TAPAS trial ${ }^{65,66}$ confirmed the clinical efficacy of the initial promising data about the functional or structural indexes of CMVO ${ }^{64}$ the TASTE trial failed to show any mortality benefit at 1 year. ${ }^{67,68}$ Eventually, the TOTAL trial has recently clarified as, in patients with STEMI undergoing primary PCI, routine manual thrombectomy as compared to PCI alone did not reduce the risk of cardiovascular death, recurrent MI, cardiogenic shock, or New York Heart Association (NYHA) class IV heart failure within 180 days but was associated with an increased rate of stroke within 30 days. ${ }^{69}$

The Angiojet mechanical thrombectomy device in the JETSTENT study showed an improvement in STR and a lower 1-year MACEs rate in the treatment group, compared to the direct stenting group..$^{70}$ Other approaches including stent with trapping capabilities ${ }^{71}$ and local delivery of abciximab at culprit lesion level through special porous balloon ${ }^{72}$ failed to improve clinical outcome. Interestingly, in a recent randomized study aimed at comparing a strategy of immediate stenting $v s$ delayed stenting, the authors showed a lower rate of CMVO and greater myocardial salvage index at 6 months in the deferred group, thus suggesting that leaving time form residual thrombus dissolution before stenting may play an important role in the prevention of $\mathrm{CMVO}^{73}$

Finally, the use of vasodilators, including verapamil, diltiazem, and nitroprusside $\mathrm{e}^{74,75}$ have been associated with improvement of flow by angiography, although clinical outcome data are lacking in calciumantagonists $^{74}$ or controversial for nitroprusside. ${ }^{75}$

\section{After catheterization laboratory}

The aggressive risk factors modifications, guidelines based therapy and rehabilitation were all proven to have a significant impact on the recurrence of ACS and re-hospitalization and may exert their effect at least in part by improving coronary microvascular function. Furthermore, some drug infusion started in the catheterization laboratory may be continued in CCU. In particular, beneficial effects have been shown for IV IIb-IIIa inhibitors, ${ }^{76}$ adenosine, ${ }^{55} \mathrm{ANP}^{60}$ and more recently exenatide. ${ }^{62}$ The duration of IV infusion for such therapies in CCU should be matter of future studies, as currently tested drugs have been administered for variable times from $3 \mathrm{~h}$ to $12 \mathrm{~h}$. More prolonged therapies (up to $24 \mathrm{~h}$ ) may possibly increase the rate of reversible CMVO, that has been described to occur spontaneously in nearly half of patients after 1 month. $^{82}$

The utility of stem cells in CMVO has provided mixed results. ${ }^{77,83}$ Indeed, improvement of CFR after cell therapy has not consistently been shown in all trials ${ }^{83}$ conversely in the presence of CMVO, the improvement of LVEF associated with stem cell treatment seems to be dampened. ${ }^{77}$
In a recent study, the addition of cilostazol (for 1 month) to double antiplatelet therapy with aspirin and clopidogrel in patients with angiographic CMVO improved the clinical outcome after 1 year. $^{78}$

The use of vasodilators (calcium-channel antagonist, dypiridamole) or metabolic drugs (ranolazine) at discharge needs future research having as end-point reversion of CMVO. ${ }^{79,80}$

Finally, a continuous effort in improvement of coronary microvascular dysfunction is mandatory as it may predict a worse outcome even when the acute coronary occlusion has been solved by coronary stenting.

\section{Conclusions}

In the last years, several evidences have pointed out that CMVO may negate the benefit of PCI in the context of STEMI. Yet, most of the trials in this setting, mainly targeting reperfusion damage, have failed to show beneficial effects. This review article revises the mechanisms, diagnosis and prognosis of CMVO in acute STEMI, also proposing the notion of an integrated approach finalized to prevent and treat CMVO in different time windows of the acute event.

\section{References}

1. Yeh RW, Sidney S, Chandra M, et al. Population trends in the incidence and outcomes of acute myocardial infarction. N Engl J Med 2010;362:2155-65.

2. Gersh BJ, Stone GW, White HD, et al. Pharmacological facilitation of primary percutaneous coronary intervention for acute myocardial infarction: is the slope of the curve the shape of the future? JAMA 2005;293:979-86.

3. Menees DS, Peterson ED, Wang Y, et al. Door-to-balloon time and mortality among patients undergoing primary PCI. N Engl J Med 2013;369:901-9.

4. Crea F. Coronary microvascular obstruction - a puzzle with many pieces. N Engl J Med 2015;372:1464-65.

5. Albertal M, Voskuil M, Piek JJ, et al. Coronary flow velocity reserve after percutaneous interventions is predictive of periprocedural outcome. Circulation 2002;105: 1573-78.

6. Herrmann J, Haude M, Lerman A, et al. Abnormal coronary flow velocity reserve after coronary intervention is associated with cardiac marker elevation. Circulation 2001;103:2339-45.

7. Lerman A, Holmes DR, Herrmann J, et al. Microcirculatory dysfunction in ST-elevation myocardial infarction: cause, consequence, or both? Eur Heart J 2007;28: 788-97.

8. Kloner RA, Ganote CE, Jennings RB. The 'no reflow' phenomenon after temporary occlusion in the dog. J Clin Invest 1974;54:1496-508.

9. Iwakura K, Ito H, Kawano S, et al. Prediction of the noreflow phenomenon with ultrasonic tissue characterization in patients with anterior wall acute myocardial infarction. Am J Cardiol 2004;93:1357-61. 
10. Frohlich GM, Meier P, White SK, et al. Myocardial reperfusion injury: looking beyond primary PCI. Eur Heart J 2013;34:1714-22.

11.Bekkers SC, Yazdani SK, Virmani R, et al. Microvascular obstruction: underlying pathophysiology and clinical diagnosis. J Am Coll Cardiol 2010;55:1649-60.

12. Reffelmann T, Kloner RA. The no-reflow phenomenon: a basic mechanism of myocardial ischemia and reperfusion. Basic Res Cardiol 2006;101:359-72.

13. Robbers LF, Eerenberg ES, Teunissen PF, et al. Magnetic resonance imaging-defined areas of microvascular obstruction after acute myocardial infarction represent microvascular destruction and haemorrhage. Eur Heart J 2013;34:2346-53.

14. Wu KC, Zerhouni EA, Judd RM, et al. Prognostic significance of microvascular obstruction by magnetic resonance imaging in patients with acute myocardial infarction. Circulation 1998;97:765-72.

15. Napodano M, Peluso D, Marra MP, et al. Time-dependent detrimental effects of distal embolization on myocardium and microvasculature during primary percutaneous coronary intervention. JACC Cardiovasc Interv 2012;5:1170-7.

16. Choi BJ, Prasad A, Gulati R, et al. Coronary endothelial dysfunction in patients with early coronary artery disease is associated with the increase in intravascular lipid core plaque. Eur Heart J 2013;34:2047-54.

17. Niccoli G, Burzotta F, Galiuto L, et al. Myocardial noreflow in humans. J Am Coll Cardiol 2009;54:281-92.

18. Vignali L, Talanas G, Saia F, et al. Genetic association between the 1976T_C polymorphism in the adenosine A2 receptor and angiographic no-reflow phenomenon (abstr). Giorn Ital Cardiol Invasiv 2007;3:109.

19. Niccoli G, Scalone G, Cosentino N, et al. Protective effect of pre-infarction angina on microvascular obstruction after primary percutaneous coronary intervention is blunted in humans by cardiovascular risk factors. Circ J 2014;78:1935-41.

20. Ambrosio G, Del Pinto M, Tritto I, et al. Chronic nitrate therapy is associated with different presentation and evolution of acute coronary syndromes: insights from 52,693 patients in the Global Registry of Acute Coronary Events. Eur Heart J 2010;31:430-8.

21. Galiuto L, Gabrielli FA, Lombardo A, et al. Reversible microvascular dysfunction coupled with persistent myocardial dysfunction: implications for post-infarct left ventricular remodelling. Heart 2007;93:565-71.

22. Yamamuro A, Akasaka T, Tamita K, et al. Coronary flow velocity pattern immediately after percutaneous coronary intervention as a predictor of complications and inhospital survival after acute myocardial infarction. Circulation 2002;106:3051-6.

23. Fearon WF, Shah M, Ng M, et al. Predictive value of the index of microcirculatory resistance in patients with STsegment elevation myocardial infarction. J Am Coll Cardiol 2008; 51:560-5.

24. Van de Hoef TP, Bax M, et al. Impact of coronary microvascular function on long-term cardiac mortality in patients with acute ST-segment-elevation myocardial infarction. Circ Cardiovasc Interv 2013;6:207-15.

25. Morishima I, Sone T, Okumura K, et al. Angiographic no-reflow phenomenon as a predictor of adverse longterm outcome in patients treated with percutaneous transluminal coronary angioplasty for first acute myocardial infarction. J Am Coll Cardiol 2000;36:1202-9.

26. Gibson CM, Cannon CP, Daley WL, et al. TIMI frame count: a quantitative method of assessing coronary artery flow. Circulation 1996;93:879-88.

27. Van't Hof AW, Liem A, Suryapranata H, et al. Angiographic assessment of myocardial reperfusion in patients treated with primary angioplasty for acute myocardial infarction: myocardial blush grade. Zwolle Myocardial Infarction Study Group. Circulation 1998;97:2302-6.

28. Gibson CM, Cannon CP, Murphy SA, et al. Relationship of the TIMI myocardial perfusion grades, flow grades, frame count, and percutaneous coronary intervention to long-term outcomes after thrombolytic administration in acute myocardial infarction. Circulation 2002;105: 1909-13.

29. Niccoli G, Cosentino N, Spaziani C, et al. No-reflow: incidence and detection in the cath-lab. Curr Pharm Des 2013;19:4564-75.

30. Schroder R. Prognostic impact of early ST-segment resolution in acute ST-elevation myocardial infarction. Circulation 2004;110:e506-10.

31. Infusino F, Niccoli G, Fracassi F, et al. The central role of conventional 12-lead ECG for the assessment of microvascular obstruction after percutaneous myocardial revascularization. J Electrocardiol 2014;47:45-51.

32. McLaughlin MG, Stone GW, Aymong E, et al. Prognostic utility of comparative methods for assessment of STsegment resolution after primary angioplasty for acute myocardial infarction: the Controlled Abciximab and Device Investigation to Lower Late Angioplasty Complications (CADILLAC) trial. J Am Coll Cardiol 2004; 44:1215-23.

33. Galiuto L, Garramone B, Scarà A, et al. The extent of micro- vascular damage during myocardial contrast echocardiography is superior to other known indexes of post-infarct reperfusion in predicting left ventricular remodeling: results of the multicenter AMICI study. J Am Coll Cardiol 2008;51:552-9.

34. Nijveldt R, Beek AM, Hirsch A, et al. Functional recovery after acute myocardial infarction: comparison between angiography, electrocardiography, and cardiovascular magnetic resonance measures of microvascular injury. $\mathrm{J}$ Am Coll Cardiol 2008;52:181-9.

35. Lautamaki R, Schuleri KH, Sasano T, et al. Integration of infarct size, tissue perfusion, and metabolism by hybrid cardiac positron emission tomography/computed tomography: evaluation in a porcine model of myocardial infarction. Circ Cardiovasc Imaging 2009;2:299-305.

36. Bax M, de Winter RJ, Schotborgh CE, et al. Short- and long-term recovery of left ventricular function predicted at the time of primary percutaneous coronary intervention in anterior myocardial infarction. J Am Coll Cardiol 2004;43:534-41.

37. Ndrepepa G, Tiroch K, Fusaro M, et al. 5-year prognostic value of no-reflow phenomenon after percutaneous coronary intervention in patients with acute myocardial infarction. J Am Coll Cardiol 2010;55:2383-9.

38. Araszkiewicz A, Grajek S, Lesiak M, et al. Effect of impaired myocardial reperfusion on left ventricular remodeling in patients with anterior wall acute myocardial infarction treated with primary coronary intervention. J Cardiol 2006;98:725-8. 
39. Henriques JP, Zijlstra F, van't Hof AW, et al. Angiographic assessment of reperfusion in acute myocardial infarction by myocardial blush grade. Circulation 2003; 107:2115-9.

40. Bolognese L, Carrabba N, Parodi G, et al. Impact of microvascular dysfunction on left ventricular remodeling and long-term clinical outcome after primary coronary angioplasty for acute myocardial infarction. Circulation 2004;109:1121-6.

41. Lombardo A, Niccoli G, Natale L, et al. Impact of microvascular obstruction and infarct size on left ventricular remodeling in reperfused myocardial infarction: a contrast-enhanced cardiac magnetic resonance imaging study. Int J Cardiovasc Imaging 2012;28:835-2.

42. De Waha S, Desch S, Eitel I, et al. Impact of early vs. late microvascular obstruction assessed by magnetic resonance on long-term outcome after ST-elevation myocardial infarction: a comparison with traditional prognostic markers. Eur Heart J 2010;31:2660-8.

43. Sorajja P, Gersh BJ, Costantini C, et al. Combined prognostic utility of ST-segment recovery and myocardial blush after primary percutaneous coronary intervention in acute myocardial infarction. Eur Heart J 2005;26:667-74.

44. Iwakura K, Ito H, Kawano S, et al. Chronic pre-treatment of statins is associated with the reduction of the no-reflow phenomenon in the patients with reperfused acute myocardial infarction. Eur Heart J 2006;27:534-9.

45. Kim JS, Kim J, Choi D, et al. Efficacy of high-dose atorvastatin loading before primary percutaneous coronary intervention in ST-segment elevation myocardial infarction: the STATIN STEMI trial. JACC Cardiovasc Interv 2010;3:332-9.

46. Pizarro G, Fernandez-Friera L, Fuster V, et al. Longterm benefit of early pre-reperfusion metoprolol administration in patients with acute myocardial infarction: results from the METOCARD-CNIC trial (effect of metoprolol in cardioprotection during an acute myocardial infarction). J Am Coll Cardiol 2014;63:2356-62.

47. Petronio AS, De Carlo M, Strata E, et al. Impact of early abciximab administration on infarct size in patients with ST-elevation myocardial infarction. Int J Card 2012;155: 230-5.

48. Ellis SG, Tendera M, de Belder MA, et al. 1-year survival in a randomized trial of facilitated reperfusion: results from the FINESSE (facilitated intervention with enhanced reperfusion speed to stop events) trial. JACC Cardiovasc Interv 2009;2:909-16.

49. Van't Hof AW, Ten Berg J, Heestermans T, et al. Prehospital initiation of tirofiban in patients with ST-elevation myocardial infarction undergoing primary angioplasty (On-TIME 2): a multicentre, double-blind, randomised controlled trial. Lancet 2008;372:537-46.

50. Botker HE, Kharbanda R, Schmidt MR, et al. Remote ischaemic conditioning before hospital admission, as a complement to angioplasty, and effect on myocardial salvage in patients with acute myocardial infarction: a randomised trial. Lancet 2010;375:727-34.

51. Rentoukas I, Giannopoulos G, Kaoukis A, et al. Cardioprotective role of remote ischemic periconditioning in primary percutaneous coronary intervention: enhancement by opioid action. JACC Cardiovasc Interv 2010;3: 49-55.

52. Mehta SR, Yusuf S, Diaz R, et al. Effect of glucose-in- sulin-potassium infusion on mortality in patients with acute ST-segment elevation myocardial infarction: the CREATE-ECLA randomized controlled trial. JAMA 2005;293:437-46.

53. Selker HP, Beshansky JR, Sheehan PR, et al. Out-ofhospital administration of intravenous glucose-insulinpotassium in patients with suspected acute coronary syndromes: the IMMEDIATE randomized controlled trial. JAMA 2012;307:1925-33.

54. Ambrosio G, Del Pinto M, Tritto I, et al. Chronic nitrate therapy is associated with different presentation and evolution of acute coronary syndromes: insights from 52,693 patient in the Global Registry of Acute Coronary Events. Eur Heart J 2010;31:430-8.

55. Kloner RA, Forman MB, Gibbons RJ, et al. Impact of time to therapy and reperfusion modality on the efficacy of adenosine in acute myocardial infarction: the AMISTAD-2 trial. Eur Heart J 2006;27:2400-5.

56. Marzilli M, Orsini E, Marraccini P, et al. Beneficial effects of intracoronary adenosine as an adjunct to primary angioplasty in acute myocardial infarction. Circulation 2000;101:2154-9.

57. Desmet W, Bogaert J, Dubois C, et al. High-dose intracoronary adenosine for myocardial salvage in patients with acute ST- segment elevation myocardial infarction. Eur Heart J 2011;32:867-77.

58. Niccoli G, Rigattieri S, De Vita MR, et al. Open-label, randomized, placebo-controlled evaluation of intracoronary adenosine or nitroprusside after thrombus aspiration during primary percutaneous coronary intervention for the prevention of microvascular obstruction in acute myocardial infarction: the REOPEN-AMI study (intracoronary nitroprusside versus adenosine in acute myocardial infarction). JACC Cardiovasc Interv 2013;6: 580-9.

59. Niccoli G, Spaziani C, Crea F; REOPEN-AMI Investigators. Left ventricular remodeling and 1-year clinical follow-up of the REOPEN-AMI trial. J Am Coll Cardiol 2014;63:1454-5.

60. Kitakaze M, Asakura M, Kim J, et al. Human atrial natriuretic peptide and nicorandil as adjuncts to reperfusion treatment for acute myocardial infarction (J-WIND): two randomised trials. Lancet 2007;370:1483-93.

61. Piot C, Croisille P, Staat P, et al. Effect of cyclosporine on reperfusion injury in acute myocardial infarction. $\mathrm{N}$ Engl J Med 2008;359:473-81.

62. Lonborg J, Vejlstrup N, Kelbaek H, et al. Exenatide reduces reperfusion injury in patients with ST-segment elevation myocardial infarction. Eur Heart J 2012;33: 1491-9.

63. Crimi G, Pica S, Raineri C, et al. Remote ischemic postconditioning of the lower limb during primary percutaneous coronary intervention safely reduces enzymatic infarct size in anterior myocardial infarction: a randomized controlled trial. JACC Cardiovasc Interv 2013;6: 1055-63.

64. Burzotta F, Trani C, Romagnoli E, et al. Manual thrombus-aspiration improves myocardial reperfusion: the randomized evaluation of the effect of mechanical reduction of distal embolization by thrombus-aspiration in primary and rescue angioplasty (REMEDIA) trial. J Am Coll Cardiol 2005;46:371-6.

65. Svilaas T, Vlaar PJ, van der Horst IC, et al. Thrombus 
aspiration during primary percutaneous coronary intervention. N Engl J Med 2008;358:557-67.

66. Vlaar PJ, Svilaas T, van der Horst IC, et al. Cardiac death and reinfarction after 1 year in the Thrombus Aspiration during Percutaneous coronary intervention in Acute myocardial infarction Study (TAPAS): a 1-year follow-up study. Lancet 2008;371:1915-20.

67. Frobert O, Lagerqvist B, Olivecrona GK, et al. Thrombus aspiration during ST-segment elevation myocardial infarction. N Engl J Med 2013;369:1587-97.

68. Lagerqvist B, Frobert O, Olivecrona GK, et al. Outcomes 1 year after thrombus aspiration for myocardial infarction. N Engl J Med 2014;371:1111-20.

69. Jolly SS, Cairns JA, Yusuf S, et al. Randomized trial of primary PCI with or without routine manual thrombectomy. N Engl J Med 2015;372:1389-98.

70. Migliorini A, Stabile A, Rodriguez AE, et al. Comparison of AngioJet rheolytic thrombectomy before direct infarct artery stenting with direct stenting alone in patients with acute myocardial infarction. The JETSTENT trial. J Am Coll Cardiol 2010;56:1298-306.

71. Stone GW, Abizaid A, Silber S, et al. Prospective, randomized, multicenter evaluation of a polyethylene terephthalate micronet mesh-covered stent (MGuard) in ST-segment elevation myocardial infarction: the MASTER trial. J Am Coll Cardiol 2012;60:1975-84.

72. Prati F, Capodanno D, Pawlowski T, et al. Local delivery versus Intracoronary infusion of Abciximab in patients with Acute Coronary Syndrome. JACC Cardiol Intv 2010;3:928-34.

73. Carrick D, Oldroyd KG, McEntegart M, et al. A randomized trial of deferred stenting versus immediate stenting to prevent no- or slow-reflow in acute ST-segment elevation myocardial infarction (DEFER-STEMI). J Am Coll Cardiol 2014;63:2088-98.

74. Huang D, Qian J, Ge L, et al. REstoration of Coronary flow in patients with no-reflow after primary coronary interVEntion of acute myocaRdial infarction (RECOVER). Am Heart J 2012;164:394-401.

75. Amit G, Cafri C, Yaroslavtsev S, et al. Intracoronary nitroprusside for the prevention of the no-reflow phenom- enon after primary percutaneous coronary intervention in acute myocardial infarction. A randomized, doubleblind, placebo-controlled clinical trial. Am Heart J 2006;152:887e9-e14.

76. Petronio AS, De Carlo M, Ciabatti N, et al. Left ventricular remodeling after primary coronary angioplasty in patients treated with abciximab or intracoronary adenosine. Am Heart J 2005;150:1015.

77. Wohrle J, von Scheidt F, Schauwecker P, et al. Impact of cell number and microvascular obstruction in patients with bone-marrow derived cell therapy: final results from the randomized, double-blind, placebo controlled intracoronary Stem Cell therapy in patients with Acute Myocardial Infarction (SCAMI) trial. Clin Res Cardiol 2013;102:765-70.

78. Lee KH, Ahn Y, Kim SS, et al. Comparison of triple anti-platelet therapy and dual anti-platelet therapy in patients with acute myocardial infarction who had no-reflow phenomenon during percutaneous coronary intervention. Circ J 2013;77:2973-81.

79. Tanzilli G, Greco C, Pasceri V, et al. Dipyridamole versus verapamil for treatment of no-reflow during primary angioplasty. Catheter Cardiovasc Interv 2010;76:787-93.

80. Pelliccia F, Pasceri V, Marazzi G, et al. A pilot randomized study of ranolazine for reduction of myocardial damage during elective percutaneous coronary intervention. Am Heart J 2012;163:1019-23.

81. Zhao JL, Yang YJ, You SJ, et al. Pre-treatment with fosinopril or valsartan reduces myocardial no-reflow after acute myocardial infarction and reperfusion. Coron Artery Dis 2006;17:463-9.

82. Galiuto L, Lombardo A, Maseri A, et al. Temporal evolution and functional outcome of no reflow: sustained and spontaneously reversible patterns following successful coronary recanalisation. Heart 2003;89:731-7.

83. Zimmet H, Porapakkham P, Porapakkham P, et al. Shortand long-term outcomes of intracoronary and endogenously mobilized bone marrow stem cells in the treatment of ST-segment elevation myocardial infarction: a meta-analysis of randomized control trials. Eur J Heart Fail 2012;14:91-105. 